\title{
Modeling and Design of Azimuth-Altitude Dual Axis Solar Tracker for Maximum Solar Energy Generation
}

\author{
Salem Alaraby Ali Shufat a, Erol Kurtb*, and Aybaba Hancerlioğullarl ${ }^{\mathrm{a}}$ \\ aBranch of Material Science and Engineering, Institute of Natural Sciences, Kastamonu University, Turkey \\ ${ }^{b}$ Department of Electrical and Electronic Engineering, Faculty of Technology, Gazi University, Turkey
}

\begin{abstract}
The sun tracking system that lets Parabolic Dish or PV panel orthogonal to the sun radiation during the day, can raise the concentrated sun radiation by up to $40 \%$. The fixed Parabolic Dish cannot generally track the sun trajectory, also the single-axis tracking system can follow the sun in the horizontal direction (azimuth angle), while the two-axis tracker tracks the sun path in both azimuth and altitude angles. Dual axis automated control tracking system, which tracks the sun in two planes (azimuth and altitude) to move a Concentrated Parabolic Dish system to the direction of ray diffusion of sun radiation is studied and designed. The designed tracking system constructed of microcontroller or programmable logic control (PLC) with a digital program that operates sun tracker using driver, gear box to control the angular speed and mechanical torque, supports and mountings. Two steeper motors are modelled to guide the parabolic dish panel perpendicular to the sun's beam. In the present study, simulation scheme of two axis sun tracking system has been developed by operating under Matlab/Simulink. The program models and studies the effectiveness of overall system. The designed tracker has been studied with real data of sun trajectory angles (azimuth and altitude) as well as a Direct Normal Irradiation (DNI) to improve the effectiveness of parabolic dish panel by adding the tracking features to those systems according to the present site.
\end{abstract}

Keywords: Azimuth, Altitude, Irradiation, sun tracking system, PDS

(C)2019. CBIORE-IJRED. All rights reserved

Article History: Received May 18 $8^{\text {th }}$ 2018; Received in revised form October $8^{\text {th }}$ 2018; Accepted January $6^{\text {th }}$ 2019; Available online

How to Cite This Article: Shufat, S.A., Kurt, E, and Hancerlioğulları, A. (2019) Modeling and Design of Azimuth-Altitude Dual Axis Solar Tracker for Maximum Solar Energy Generation. Int. Journal of Renewable Energy Development, 8(1), 7-13.

https://doi.org/10.14710/ijred.8.1.7-13

\section{Introduction}

Energy demand rapidly increases for developing countries although it is more stable for the developed countries. The increase in industrial activities and population growth play important role on that trend (Akizu et al. 2018; Bouzelata et al 2016). Although the conventional energy resources such as oil, gas and coal are used to fulfil the public requirements, increasing carbon release and depending environmental issues put a threshold for the conventional resources (Kurt et al 2016; Raasakka 1997). On the other hand, due to the decrease in world reserve and increasing cost also affect the availability to these resources world-widely. All these aspects motivate the engineers and academicians to explore renewable energy resources for the present and future demand on energy deficit. Among the renewable resources, solar, wind, geothermal, hydrogen, hydro, tidal, geothermal, and energy harvesting can be mentioned. By considering the resources above, the most promising one is solar energy. Note that the energy emission of Sun is $3.81023 \mathrm{~kW} / \mathrm{s}$. However, only a small amount about $1.81014 \mathrm{~kW}$ is intercepted by the Earth because of the location of earth about 150 million $\mathrm{km}$ farther the Sun. Even nearly $60 \%$ of this power (ie. 1.08
1014) reaches at the surface of the planet (Kowalski 1997). Indeed, the rest is reflected back into space and absorbed by Earth atmosphere. Even if only $0.1 \%$ of this power could be converted at an efficiency of only $10 \%$, it would be four to five times the world's total produced power with $3000 \mathrm{GW}$. On the one hand, the total annual solar irradiation radiating on the earth is more than 7500 times the world's total yearly major energy consumption of 450 EJ (Popat and Arlington 1998). Therefore, solar energy can be considered as the most convenient renewable resource for future energy perspectives.

In the present world, solar energy systems including photovoltaics and solar concentrating systems have been considered as the most applicable solution in terms of industrial and domestic applications. In the solar concentrating systems, a solar collector, which is subject to collect the radiation of sun and convert it into either thermal energy or electrical power has been used (Raasakka et al 1997; Kowalski 1997; Popat and Arlington 1998; Badescu 1998). Many studies in the literature concerning to the use of solar collectors to realize such applications as light fixtures window covering systems cookers and so forth (Popat and

\footnotetext{
* Corresponding author: ekurt52tr@yahoo.com
} 
Arlington 1998; Badescu 1998; Algifri and Al-Towaie 2001). Generally, the developed power in such applications depend basically upon the amount of solar energy captured by the collectors, and thereby, the necessity of design and development in solar tracking systems should be capable to follow the sun trajectory during the day on a year-round basis and that gets strong attention from the energy community. Solar energy is not constant at any direction during a day because of sun movement, whereas solar power generation system uses specific sun tracking system and that makes the available energy higher compared to the standard stable systems. One way to increase the efficiency of a solar energy dish is to manufacture the dish system by using different effective materials. The second way is to track the sun by using an efficient and fast-respond solar tracker. In that context, for example several systems have been suggested for optimizing the slop angle and direction of solar collectors designed for different geographical latitudes or possible utilization periods (Hj et al 2001; Bari 2000).

Solar power generation by using a controllable moving dish is an efficient solution. When Earth is rotating, solar radiation reaching at the collectors cannot be constant at any direction in the entire day. Therefore, tracking the solar energy in each direction increases the efficiency of the system. Indeed, a solar tracker is an automated solar panel, which assists to get maximum radiation for entire day (Appleyard 2009).

The efficiency of a concentrated dish, which is mostly subject to a Stirling engine - based energy production scheme can be improved by using a dual axis tracking system. In this regard, dual axis tracking system is the best choice for tracking in both azimuth and altitude directions. That also works well even during a cloudy season in comparison with a traditional single axis tracker $(\mathrm{Hj}$ et al 2001).

The designed two-axis sun tracking system is distinguished by a reasonable simple and low-cost electromechanical system with low maintenance requirement, easy-installation and operational aspects. Besides, the hardware and software of the tracker do not require any refreshment, when a seasonal change occurs for the position of Sun. Frankly speaking, the designed system consists of a GPS, determining the location, a microcontroller or a programmable logic controller (PLC) for storage software and the real data for Sun trajectory. The mechanical switches, performed via two step motors moving in the parabolic dish in the azimuth angle parallel with the horizontal plane as well as in the altitude plane vertical to the horizon are also vital components. These two dimensional moves permit the concentrated dish to move up/down and left/right during the daylight. Two motors are connected with a simple gear box to control the rotational speed and mechanical torque. With rapid advances in the computer technology and systems, control fields in recent decades, the literature contains many advanced sun tracking systems designed to maximize the efficiency of solar thermal and photovoltaic systems (Ponniran et al 2011; Oo et al 2010; Appleyard 2009; Ponniran et al 2011). Generally speaking, these systems can be stated as either open loop or closed loop systems depending on their needed mode of operation. Designed system in this paper represents a systematic review of the operational principles and advantages of each of the major closed loop and open loop types of sun tracking systems. Closed loop types of sun tracking systems presented in the literature through the past 20 years are based on feedback control principles. These closed loop tracking systems are using sensors which detect relevant parameters induced by the sun manipulated to transfer number of inputs to a controller and then yield outputs (i.e. sensor-based). While an open loop types of controller compute their inputs into a system using only programmed algorithm of the system and without using feedback to Determine if its input has achieved the desired aim, where the algorithm based the system is cheaper and simpler than the closed loop type of sun tracking systems. It does not observe the output of the processes that it is controlling. Thus, disadvantage of an open loop system is disability to correct errors, so that it can work under a programmed algorithm and cannot usually compensate for disturbances in the system. Open loop control algorithms of sun tracking systems use solar irradiation geometry of sun trajectory model (McCluney and Passive 1983).

In the present study, advantage of a dual axis solar tracking system is discussed, because Sun changes its position in the sky due to the rotation of Earth in daily basis and it even becomes more complicated in a seasonal basis (Oo and Hlaing 2010). By the help of a dual axis solar tracking system, one can improve the efficiency of the solar power as will be pointed out. Dual axis solar tracking system especially works well, even if the weather becomes cloudy, when it is compared to the single axis solar tracking system (Ponniran et al 2011; Oo and Hlaing 2010). Among the tracker tools, single axis trackers have a disadvantage, because the location of Sun changes in the sky with a change in altitude angle, seasonally as well as with azimuth angle during the day. However, such a system only follows daily direction (Appleyard 2009).

\section{Design of dual axis sun tracking system}

A solar tracking platform with an electric controller continually follows the position of the Sun. Indeed, during that process, the sun trajectory information is required. The concept of Sun trajectory data would be discussed, where it contains the azimuth and altitude angles for a specific location of the Global Positioning System (GPS) on Earth. Thus, one has to define a socalled solar positioning algorithm which aims to track the Sun as a source of solar energy and track its clear movement in the sky. For that reason, a real data for a sun trajectory would be provided and an electromechanical mechanism is designed as well (Prinsloo and Dobson 2015).

The designed tracking systems should be capable to follow the sun location at the accurate angle even for cloudy climate conditions. Different solar tracking techniques were suggested so far in order to increase the obtained energy for solar harvesting systems. Closed-loop solar tracker normally generates a greater tracking accuracy in the optical tracking systems, where the complex structure with low stability is the major defect. In the present study, the design concentrates on an open loop solar tracking system, where the Sun trajectory is found from an astronomical algorithm and stored as constant data for the current location. Indeed, the closed loop tracker loses feedback signals and therefore it can follow the direction of the Sun, if the sensor is shaded or inactive due to clouds. Therefore, the philosophy for the 
tracking is an open loop to use open loop sensors or algorithms, thereby, the sensors are not affected by clouds or seasonal changes. An open loop sensor such as an encoder ensures that the equivalent dish is set directly in the direction of the calculated Sun trajectory, obtained from a special table or algorithm (Chong et al 2014).

The tracking system follows the Sun with a particular degree of precision and moves the dish to its main location at the end of the day by a motor system. Fig. 1 sketches the parabolic dish system with dual axis tracking.

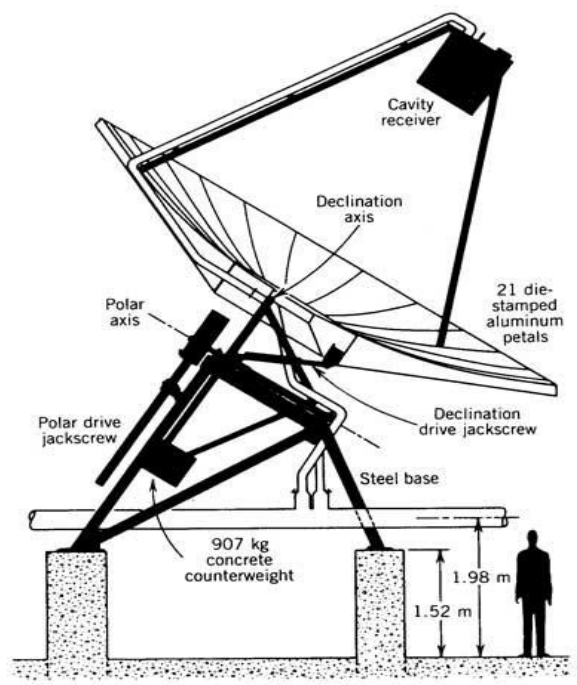

Fig. 1 Schematic diagram of Parabolic dish using dual axis sun tracking system (William and Michael 2001).

\subsection{Design of the electromechanical part}

Fig. 2 illustrates the designed open loop Sun tracker software - based tracking algorithm (Chi et al 2009; Sarker et al 2010).

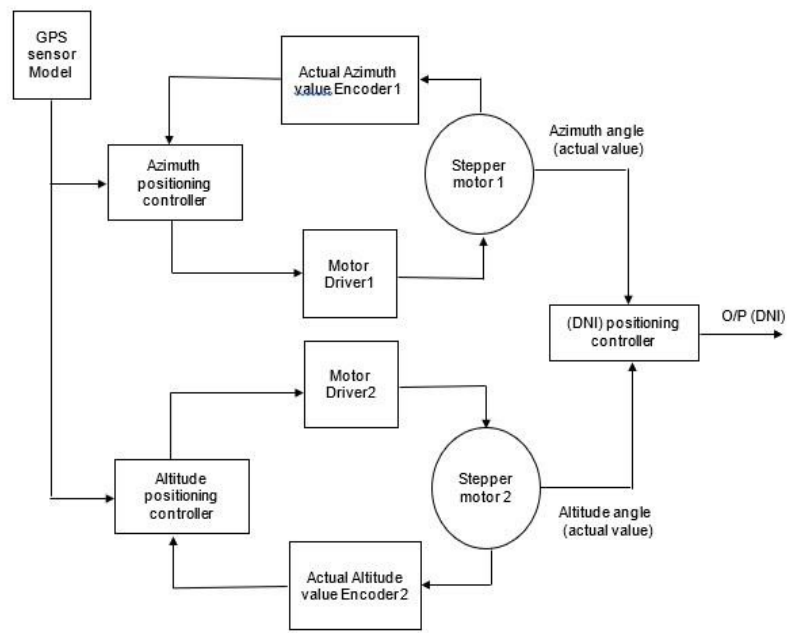

Fig. 2. Algorithm of designed dual axis sun tracking system

The main components are a GPS to determine the location, stored software and sun trajectory real data table (with azimuth and altitude angles) by using a microcontroller or a programmable logic controller (i.e. PLC), two mechanical limit switches, two steeper motors of $0.25^{\circ}$ per step as drivers. First motor for the rotation about the vertical axis (altitude angle), the second one for the East-West tracking motion (azimuth angle), each of them is connected with gear boxes to control the rotational speed and mechanical torque, and a feedback angular position sensor.

Table 1

Altitude, and Azimuth real data for Al-Koufra/Libya

\begin{tabular}{|c|c|c|}
\hline \multicolumn{3}{|c|}{$\begin{array}{l}\text { Astronomical Applications Dept. } \\
\text { U.S. Naval Observatory } \\
\text { Washington, DC 20392-5420 } \\
\text { KUFRA LIBYA: Altitude: E } 24 \text { 20, Azimuth: N23 } 28 \\
\text { Jul 15, } 2017\end{array}$} \\
\hline Time & Altitude & Azimuth \\
\hline 05:00 & -10.1 & 61.1 \\
\hline 05:30 & -4.0 & 64.5 \\
\hline 06:00 & 2.5 & 67.5 \\
\hline $06: 30$ & 8.8 & 70.3 \\
\hline 07:00 & 15.3 & 72.8 \\
\hline $07: 30$ & 21.9 & 75.1 \\
\hline 08:00 & 28.5 & 77.4 \\
\hline 08:30 & 35.3 & 79.5 \\
\hline 09:00 & 42.0 & 81.6 \\
\hline 09:30 & 48.9 & 83.7 \\
\hline $10: 00$ & 55.7 & 85.9 \\
\hline $10: 30$ & 62.6 & 88.3 \\
\hline $11: 00$ & 69.4 & 91.2 \\
\hline $11: 30$ & 76.3 & 95.6 \\
\hline $12: 00$ & 83.1 & 105.5 \\
\hline $12: 30$ & 88.0 & 188.8 \\
\hline $13: 00$ & 82.5 & 255.9 \\
\hline $13: 30$ & 75.7 & 264.9 \\
\hline $14: 00$ & 68.8 & 269.0 \\
\hline $14: 30$ & 62.0 & 271.9 \\
\hline $15: 00$ & 55.1 & 274.3 \\
\hline $15: 30$ & 48.2 & 276.4 \\
\hline $16: 00$ & 41.4 & 278.5 \\
\hline $16: 30$ & 34.6 & 280.6 \\
\hline $17: 00$ & 27.9 & 282.8 \\
\hline $17: 30$ & 21.2 & 285.0 \\
\hline $18: 00$ & 14.7 & 287.4 \\
\hline $18: 30$ & 8.2 & 289.9 \\
\hline 19:00 & 2.0 & 292.7 \\
\hline $19: 30$ & -4.6 & 295.7 \\
\hline $20: 00$ & -10.7 & 299.1 \\
\hline
\end{tabular}

\subsection{Direct Normal Irradiation (DNI) data}

It is a magnitude of solar radiation acting on unit area of a surface that is always perpendicular to the straight rays that come from the current Sun location. Generally, magnitude of irradiance received by a surface can be maximized by keeping it perpendicular to incoming radiation during the daylight. This quantity is of certain concern for concentrating solar structures and systems. Irradiance is a value of sun energy and is known as the rate at which solar energy drops onto a surface, so irradiance is represented as $\left(\mathrm{W} / \mathrm{m}^{2}\right)$. If the Sun gives a steady value of $1000 \mathrm{~W} / \mathrm{m}^{2}$ during one hour, we can say that it has a transmission rate $1 \mathrm{kWh} / \mathrm{m}^{2}$ of energy.

Measuring the devices for solar radiation called "pyranometers" are accurate and expensive; A "pyranometer" is essentially a flat plate, covered with a transparent roof, and plated by highly absorbent face. As 
Citation: Shufat, S.A., Kurt, E, and Hancerlioğulları, A. (2019) Modeling and Design of Azimuth-Altitude Dual Axis Solar Trackerfor Maximum Solar Energy Generation, Int. Journal of Renewable Energy Development, 8(1), 7-13, doi.org/10.14710/ijred.8.1.7-13

$\mathrm{P}$ a g e $\mid 10$

the sun strikes it, the surface gets hot. The surface temperature is measured with a thermopile, giving an output voltage proportional to the magnitude of solar energy acting on the surface [chuck-wright consulting]. In our work instead, we downloaded real (DNI) data as a constant data regards to a chosen site as shown in Table 1 (Photovoltaic geographical information system).

\subsection{Sun trajectory angles (Azimuth and Altitude) data}

The solar trajectory moves from east to west and the Sun movement can be clarified for a geographical position (i.e. GPS). The tracking mechanism uses the Sun trajectory data in order to follow it for a parabolic dish. For that, the trajectory from a given geographical location should be clearly studied, analyzed and understood. Azimuth and altitude angles are two parameters which define the position of Sun or Moon in the sky as appeared from a specific location at a particular time as in Figure 3(a).

Table 2

DNI, real data for Al-Koufra/Libya

\begin{tabular}{cc}
$\begin{array}{c}\text { Astronomical Applications Dept. } \\
\text { U.S. Naval Observatory } \\
\text { Washington, DC 20392-5420 }\end{array}$ \\
KUFRA LIBYA: $\begin{array}{c}\text { Altitude: E 24 20, Azimuth: N23 28 } \\
\text { Jul 15, 2017 }\end{array}$ \\
\hline Time & Altitude \\
\hline $00: 53$ & 000.0 \\
$01: 53$ & 000.0 \\
$02: 53$ & 000.0 \\
$03: 53$ & 000.0 \\
$04: 53$ & 385.91 \\
$05: 53$ & 580.9 \\
$06: 53$ & 700.93 \\
$07: 53$ & 774.34 \\
$08: 53$ & 817.44 \\
$09: 53$ & 837.57 \\
$10: 53$ & 840.93 \\
$11: 53$ & 823.99 \\
$12: 53$ & 785.09 \\
$13: 53$ & 714.09 \\
$14: 53$ & 603.09 \\
$15: 53$ & 424.05 \\
$16: 53$ & 100.62 \\
$17: 53$ & 70.02 \\
$18: 53$ & 10.06 \\
$19: 53$ & 000.0 \\
$20: 53$ & 000.0 \\
$21: 53$ & 000.0 \\
$22: 53$ & 000.0 \\
$23: 53$ & 000.0 \\
\hline
\end{tabular}

Altitude angle: It ranges from $0^{\circ}$ to $90^{\circ}$ degrees, and represents the angle between the horizontal plane and Sun. The Sun has $0^{\circ}$ degrees altitude, when it is on the horizon, while it is directly overhead when it is at $90^{\circ}$ degrees altitude.

Azimuth angle: It performs the main direction in which the sun can appear. It varies between $0^{\circ}$ and $360^{\circ}$ degrees. $0^{\circ}$ degrees would be at north, $90^{\circ}$ at east, $180^{\circ}$ at south, and $270^{\circ}$ at west position. In this paper, we have considered the real data for Koufra city as case study according to Tables 2 (Astronomical applications department)

Fig. 3(b) shows the sketch of altitude and azimuth geometry. Here hour angle for the Summer solstice is at left hand-side and the Winter solstice is at the right hand side. It clearly represents the angle changes required for the solar tracking process, while the solar tracking speed (degrees per minute) equals to the partial differential of the angle curves.

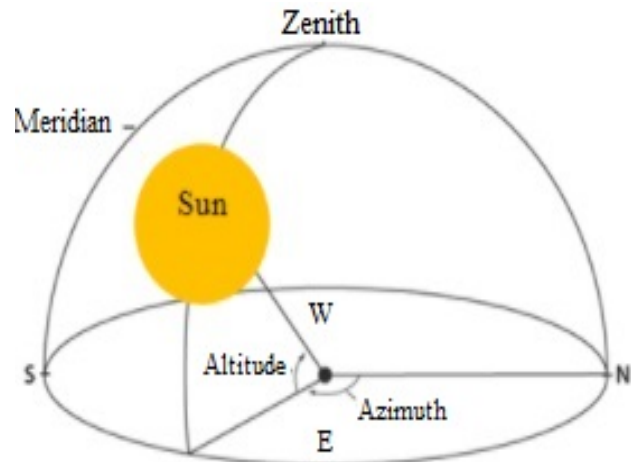

(a)

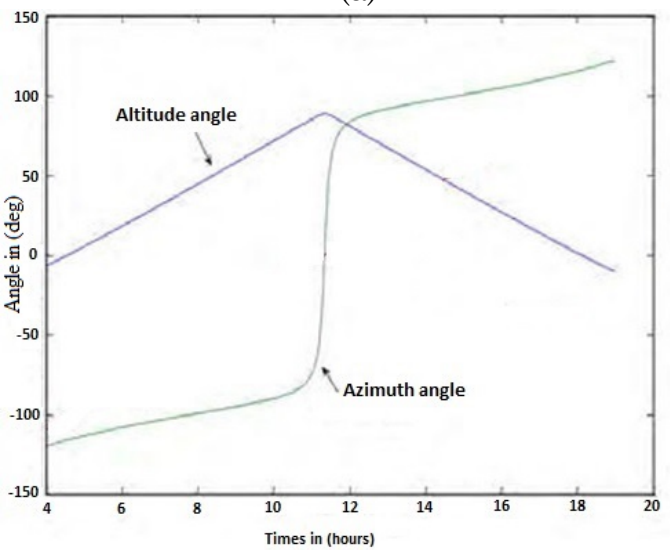

(b)

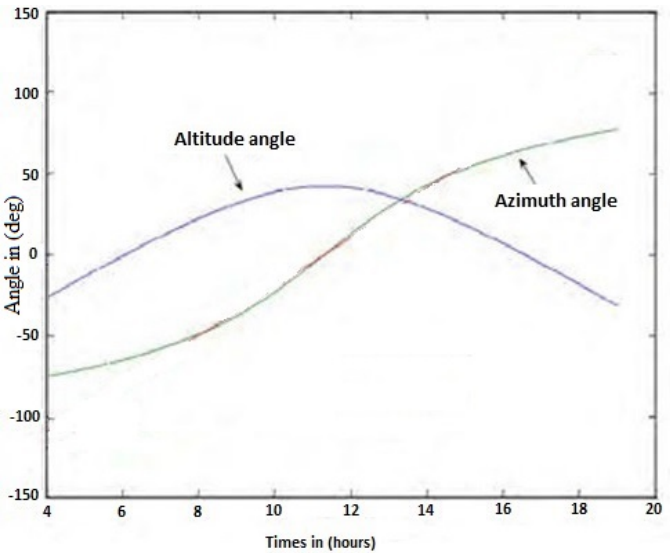

(c)

Fig 3. (a)Sketch of angles azimuth and altitude. Elevation and Azimuth angles of sun trajectory during the daytime for (a) the summer solstice and (c) the winter solstice for the same geographical location (Oo and Hlaing 2010).

\section{Simulation results for prepared blocks}

The overall dual axis sun tracker including control system, tracking mechanism, real data table of DNI and sun trajectory (azimuth and altitude angles) has been 
studied and modeled by using Matlab \& Simulink as shown in Fig. 4. Azimuth and elevation tracking mechanisms are controlled by Sun tracking control system by using designed electromechanical equipment including two step motors and gearbox. Fig. 4 represents a complete tracking system, where the input data are azimuth and elevation angles. The output step values acting directly to the stepper motor, where the output of the stepper motor is mechanical torque, angular speed, and step angles. Output step values of the angles interpolate the DNI lookup table to extract operational DNI acting directly to the concentrated dish.

To design the sun tracker mechanism, we have initially computed the Sun movement as well as a DNI data in Koufra/Libya as a case study during a chosen day (i.e. 15 July) by using Sun trajectory computation procedure (i.e. Astronomical Application Dept. U.S. Naval Observatory Washington, DC 20392-5420). That is, we used computed data of Sun position in azimuth and elevation. In our location, the azimuth angle varies from $61.1^{\circ}$ to $299.1^{\circ}$ and altitude angle varies from $-10.1^{\circ}$ to $10.7^{\circ}$ during that day in Koufra. These ranges were used to define the minimum driving ranges of the sun tracking mechanism, also for Sun move, where the maximum angular speed is required in designing sun tracking mechanism should be defined.

Fig. 5(a-c) shows the rate of changes in DNI, azimuth and altitude during the day in Koufra, respectively. Those are used as input data to our designed system. From Fig. 5(a), it can be noted that DNI is started usually at sunrise time, increasing up to maximum value at noon, then, it starts to decrease till sunset. Maximum value of DNI usually depends on the location itself and the season, where its maximum value is high in summer and low in winter.

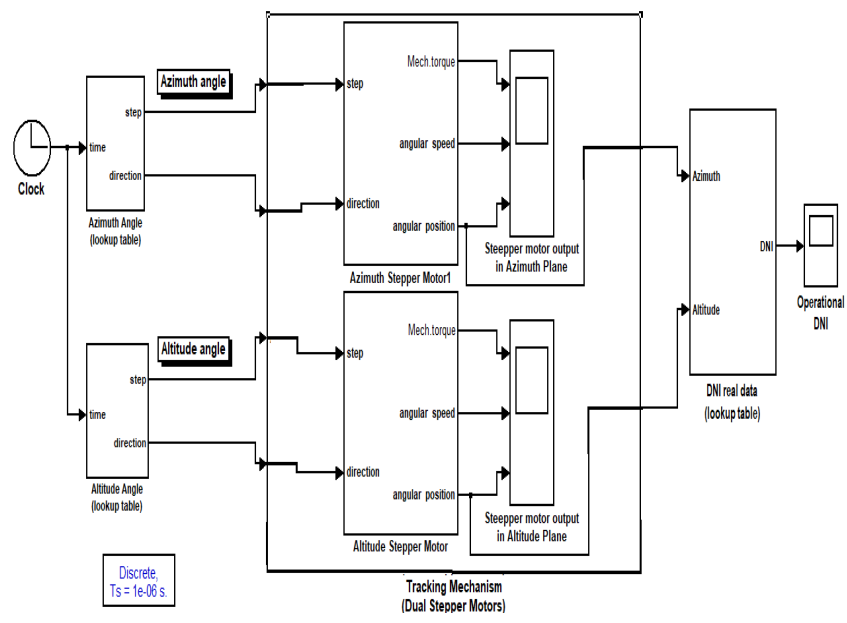

Fig 4. Simulation block diagram of dual axis sun tracking system.

Azimuth angle representing the motion of the sun in horizon plane started at west and increasing up to the maximum value at west as in Fig. 5(b). A sharp increase at noon depends on summer and winter solstice as explained in Fig. 3. Altitude angle representing the position of Sun in vertical plane starts at the sunrise angle below the horizon (normally with minus sign), increasing up to maximum value (less than $90^{\circ}$ ), then decreasing as shown in Fig. 5(c).

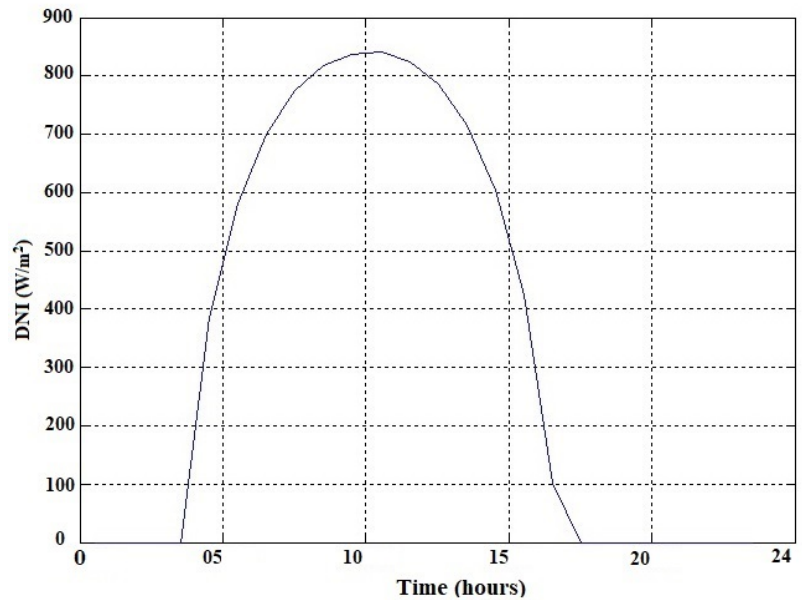

(a)

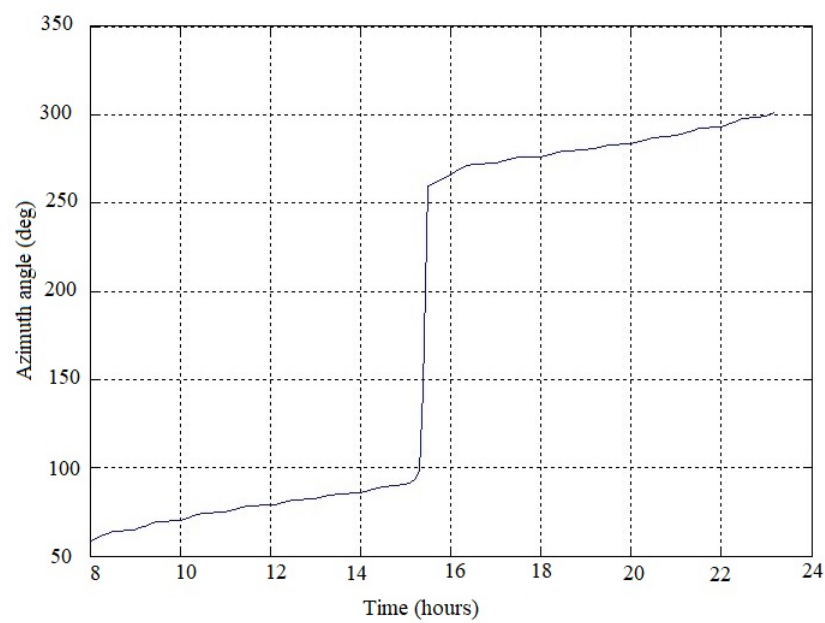

(b)

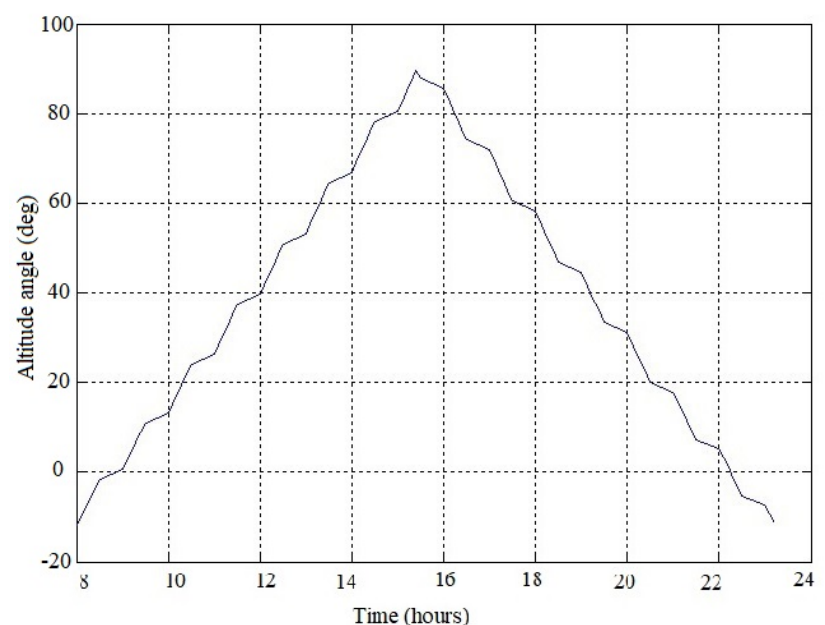

(c)

Fig 5. Real data in Al-Koufra/Libya for (a)DNI, (b)azimuth angle, and (c)altitude angle.

In the tracker, the concentrated solar dish system utilizes solar power by rotating using two stepper motors in the azimuth angle parallel with the horizonal plane as well as in the altitude angle vertical to the horizonal plane. This dual axis tracker has been designed to enforce the parabolic dish in an up and down directions (altitude angle), and from left to right (azimuth angle) in order to track the sun motion in both directions during the day. Stepper motor works according to the change of 
Sun trajectory input data. Fig. 6(a,b) determines the output of the stepper motor. The mechanical torque required to move the parabolic dish, angular speed equals to the rate of change of the sun movement during the day, and step angles of azimuth (left to right direction) and the altitude (upwards or downwards) that move the parabolic dish to its desired position are shown in Figure 6(a,b), respectively. Mechanical torque and angular speed have a reverse relation, that is, when input simulation torque to stepper motor is low, output rotational speed is high, while the output mechanical torque required is low, it is vice versa as shown in Fig. 7. Normally, choosing of output mechanical torque and angular speed depend on the size and weight of the parabolic dish by considering the rate of change in Sun move during the day.

Solar tracker axis should realize an angular rate of motion with at least $0.25 \% \mathrm{~min}$ to follow the relative sun movement. To achieve that angular rate, the minimum rotational speed $0.000694 \mathrm{rpm}$ is required to perform successful solar tracking.
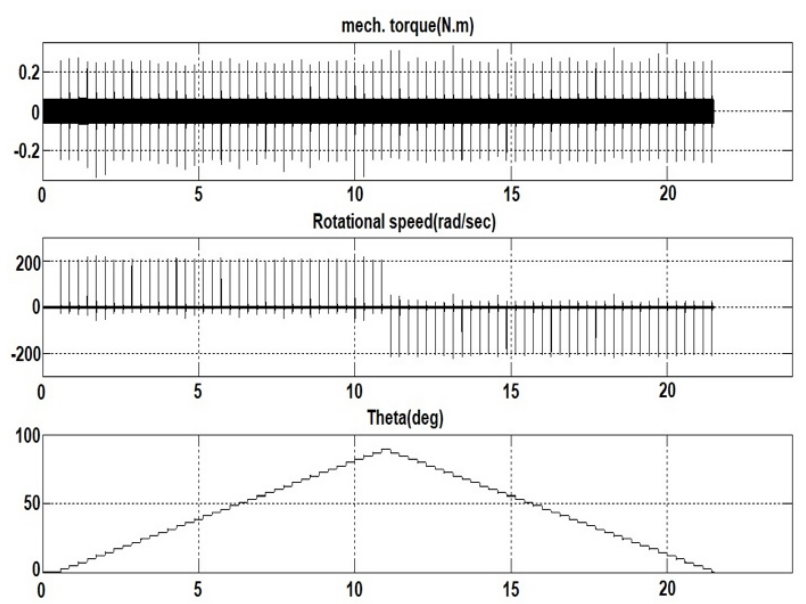

(a)
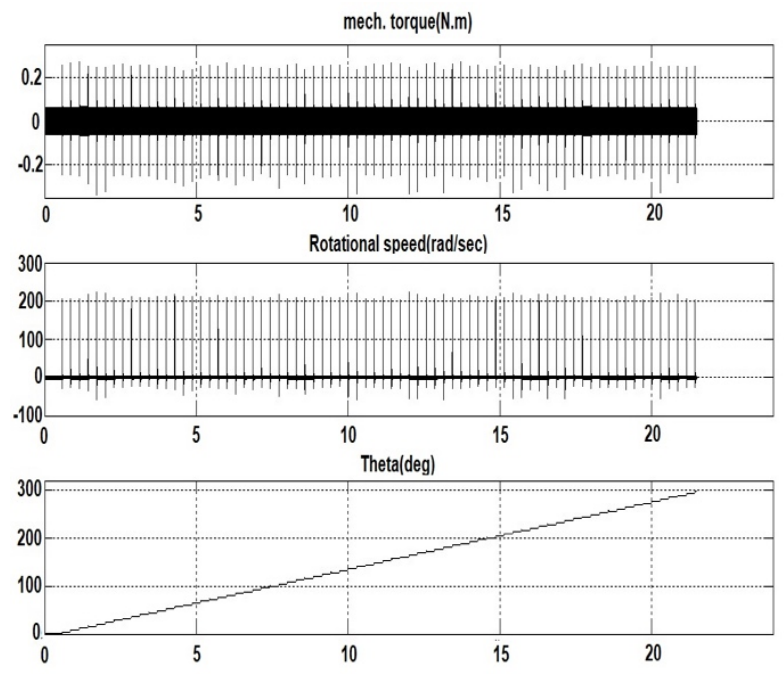

(b)

Fig 6. Time-depended operation of the stepper motors for (a) the altitude and (b) the azimuth angle directions.

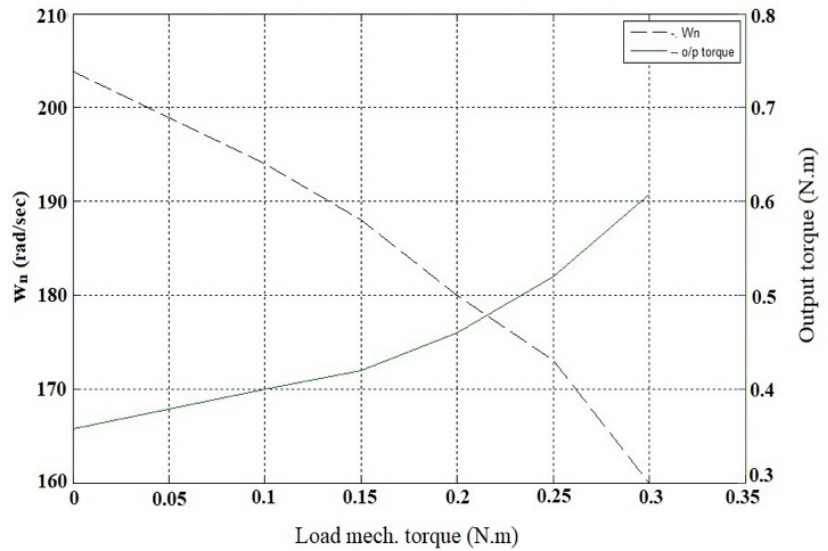

Fig 7. Effect of load mechanical torques versus rotational speed and stepper motor speed.

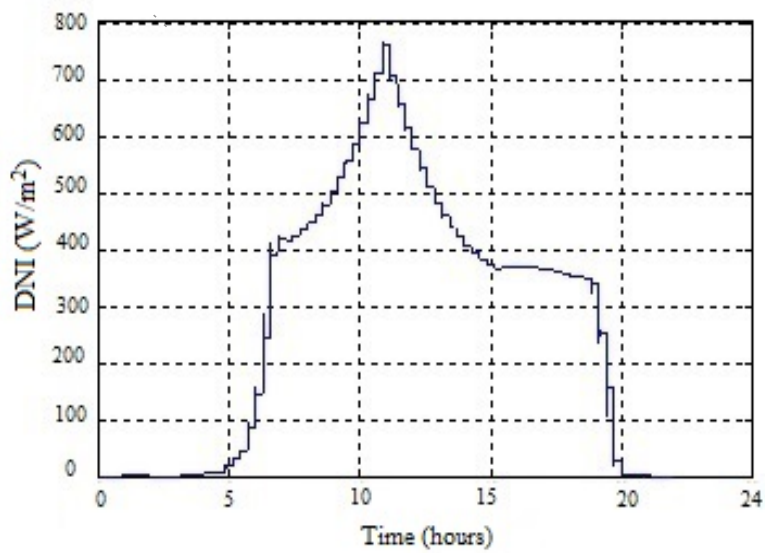

Fig 8. Output operational DNI (w/m2) acting to the parabolic dish.

Generally, the motor speed is typically around 1750$2000 \mathrm{rpm}$. This means that using an electrical motor directly would not achieve such slow rate of move with appropriate required torque to drive the mechanism. For this reason, a gear box or transmission device is necessarily required to decrease motor speed, while providing appropriate mechanical torque with slower solar tracking speed. Fig. 8 represents the output operational DNI, acting directly on the dish. Operational DNI equals to a percent (80 90\%) of the real Sun DNI. Thus, it covers a good efficiency. It is started at 05:00 am at sunshine and increasing to reach maximum value at noon, then decreased again upto 20:00 pm. The magnitude changes step by step with a stepper motor move and with respect to the changing of Sun trajectory.

\section{Conclusions}

For an open loop Sun tracking system, an electromechanical system has been designed. By using azimuth and altitude data for DNI values of Kufra city in Libya, the simulations have been carried out with a high efficiency. The complete system run in Matlab Simulink environment. The proposed system tracks Sun with a particular degree of precision, returning the dish to its original position at the end of the day. The designed open loop sun tracking mechanism uses the real data obtained from a special table and algorithm. It does not require any feedback. That open loop approach is observed to 
have an advantage for that there is no need to change or modify the hardware or software of the system in case of seasonal changes or in cloudy days. Indeed, that makes the proposed system reliable, flexible and cost-effective. The proposed algorithm can follow the driving mechanism including motor, speed reduction gears, bearing and the mechanical torque and angular speed can be recorded for the move of the parabolic dish. However, one should consider the driving mechanism, dimensions and total weight of concentrator dish as a following study.

\section{References}

Akizu, O., Bueno, O., Barcena, I., Kurt, E., Topaloglu, N. \& Lopez - Guede, J.M. (2018) Contributions of Bottom-Up Energy Transitions in Germany: A Case Study Analysis, Energies, 11, 849, doi:10.3390/en11040849

Algifri A, \& Al-Towaie H, (2001) Efficient orientation impacts of box-type solar cooker on the cooker performance. Solar Energ. 70, 165-170.

Appleyard D, (2009) Solar trackers: Facing the sun, Renewable Energy World, vol. 12, no. 3, pp. 41-53.

Astronomical applications department http://aa.usno.navy.mil/ data/ docs/AltAz.php.

Badescu V, (1998) Different strategies for maximum solar radiation collection on Mars surface. Acta Astronaut. 43, 409-421.

Bari S, (2000) Optimum slope angle and orientation of solar collectors for different periods of possible utilization. Energy Convers. Manage. 41, 855-860.

Bouzelata, Y., Altin, N., Chenni, R. \& Kurt, E. (2016) Exploration of optimal design and performance of a hybrid wind-solar energy system, Int. J. Hydrogen Energy, 41, 12497-12511, doi.org/10.1016/j.ijhydene.2015.12.165

Chuck-wright consulting http://Chuck-Wright .com /projects/PVmeasures .html.

Chi A, Yen L, Po-Cheng C, Che-Ming C, \& Chiu-Feng L, (2009) Sun tracking systems: A Review, Sensor, 9(05), 3875-3890; doi:10.3390/s90503875.

Chong K, Wong C, Tunku U, \& Rahman A, (2014) General Formula for On-Axis Sun-Tracking System. Universiti Tunku Abdul Rahman Malaysia, Chapter 3, pp. 263-291.

Hj Mohd, Yakup M, \& Malik, A.Q. (2001) Optimum tilt angle and orientation for solar collector in Brunei Darussalam. Renew. Energ. 24, 223-234.

Kowalski S, (1997) Solar powered light fixture. Renew. Energ. $11,399$.

Kurt, E., Gor, H. \& Doner, U. (2016) Electromagnetic design of a new axial and radial flux generator with the rotor backirons, 41(17), 7019-7026, 10.1016/j.ijhydene.2016.02.034

McCluney, R. (1983) Passive optical solar tracking system. Appl. Optics, 22, 3433-3439.

Oo L. L., \& N. K. Hlaing, (2010) Microcontroller-based two-axis solar tracking system, in Computer Research and Development, 2010, Second International Conference on, pp. 436-440, IEEE, 2010.

Photovoltaic geographical information system Mhttp://re.jrc.ec.europa.eu/pvg_tools/en/tools.html \#HR.

Ponniran A., Hashim A., \& Joret A., (2011) A design of low power single axis solar tracking system regardless of motor speed, International Journal of Integrated Engineering, vol. 3 , no. 2.

Popat P, \& Arlington V. (1998) Autonomous, low-cost, automatic window covering system for daylighting applications. Renew. Energ. 13, 146.

Prinsloo. G. J, \& Dobson. R. T, (2015) Solar Tracking. Solar Books 1-542, doi:10.13140/RG.2.1.4265.6329/1.

Raasakka B, (1997) Solar skylight apparatus. Renew. Energ. 12, 117.

Rustom M, Nijmeh S, \& Abdallah S, (2006) A Programmable Logic Controller to control Two Axis Sun Tracking system, Information Technology Journal, Vol. 5, pp. 1083 - 1087.
Sarker M, Pervez M, Beg A, (2010) Design, Fabrication and Experimental Study of a Novel Two-Axis Sun Tracker, International Journal of Mechanical \& Mechatronics Engineering IJMME-IJENS Vol: 10 No: 01.

Sidek M, Hasan W, Kadir M, Shafie S, Radzi M, Ahmad S, \& Marhaban M, (2014) GPS Based Portable Dual - Axis Solar Tracking System Using Astronomical Equation, IEEE International Conference Power \& Energy (PECON)

Wen J, \& Smith T, (2002) Absorption of solar energy in a room. Solar Energy, 72, 283-297.

William B, \& Michael G, (2001) Power from the sun, January, http://www.powerfromthesun.net/book.html 